\title{
Preliminary Study on Porous High-Manganese 316L Stainless Steel Through Physical Vacuum Dealloying
}

\author{
Yibin $\operatorname{Ren}^{1} \cdot \operatorname{Jun~} \mathrm{Li}^{1} \cdot \mathrm{Ke} \mathrm{Yang}^{1}$
}

Received: 15 February 2017/Revised: 3 May 2017/Published online: 30 May 2017

(C) The Chinese Society for Metals and Springer-Verlag Berlin Heidelberg 2017

\begin{abstract}
In this study, porous stainless steel was prepared successfully by physical vacuum dealloying method. The based alloy is high-manganese $316 \mathrm{~L}-50 \mathrm{Mn}$ alloy. The porous high-manganese $316 \mathrm{~L}$ stainless steel showed a three-dimensional continuous porous structure with 1-2 $\mu \mathrm{m}$ pore size. Temperature was the key factor for the physical dealloying process to produce porous stainless steel, and the optimized treatment temperature was between 800 and $850{ }^{\circ} \mathrm{C}$ for the highmanganese 316L-50Mn alloy.
\end{abstract}

KEY WORDS: Porous metals; Dealloying; Sublimation; Stainless steel; Manganese

\section{Introduction}

Porous metallic materials have low densities and novel physical properties, which were applied to lots of fields [1] ranging from lightweight construction to fuel cell [2], chemical filtration [3], catalysis [4, 5] and biomedical implants [6]. Porous stainless steel, one of the porous metals, is an interesting alternative for separation processes where organic polymer membranes suffer from limited stability because of combinations of high chemical, thermal and mechanical strength stability. Other distinct properties of porous stainless steel are their weldability, electrical and thermal conductivities. It was also used as ceramic layers support as a mechanical framework for solid oxide fuel cells [7].

At present, porous stainless steel was usually obtained by means of compaction and powder sintering technologies or powder metallurgy (P/M) methods [8]. Some investigations

Available online at http://link.springer.com/journal/40195

Yibin Ren

ybren@imr.ac.cn

1 Institute of Metal Research, Chinese Academy of Sciences, Shenyang 110016, China have been carried out to fabricate porous $316 \mathrm{~L}$ stainless steel $[8,9]$. Recently we have developed a novel physical dealloying process by using brass to produce porous copper in dynamic vacuum atmosphere [10-13].

Dealloying is demonstrated to be very efficient in producing a kind of three-dimensional (3D) porous metals based on chemical or electrochemical principle. However, the physical dealloying is based on sublimation and Kirkendall effect. Precursor alloys used in physical dealloying must contain more than one metal element with a high vapor pressure, which can be easily sublimated at a specified temperature in vacuum environment. With a vacuum heat treatment, matrix metals undergo sublimation and differential diffusion to form voids and finally form a 3D micron porous structure with interconnected ligaments. In this study, a micron porous high-manganese 316L stainless steel was prepared using a highmanganese $316 \mathrm{~L}-50 \mathrm{Mn}$ alloy by physical dealloying and the micro-topography and some influence factors were studied.

\section{Materials and Methods}

The high-manganese $316 \mathrm{~L}-50 \mathrm{Mn}$ alloy was melted in a $1-\mathrm{kg}$ vacuum induction melting furnace under argon gas pressure, with weight ratio of $1: 1$ for $316 \mathrm{~L}$ stainless steel and pure 


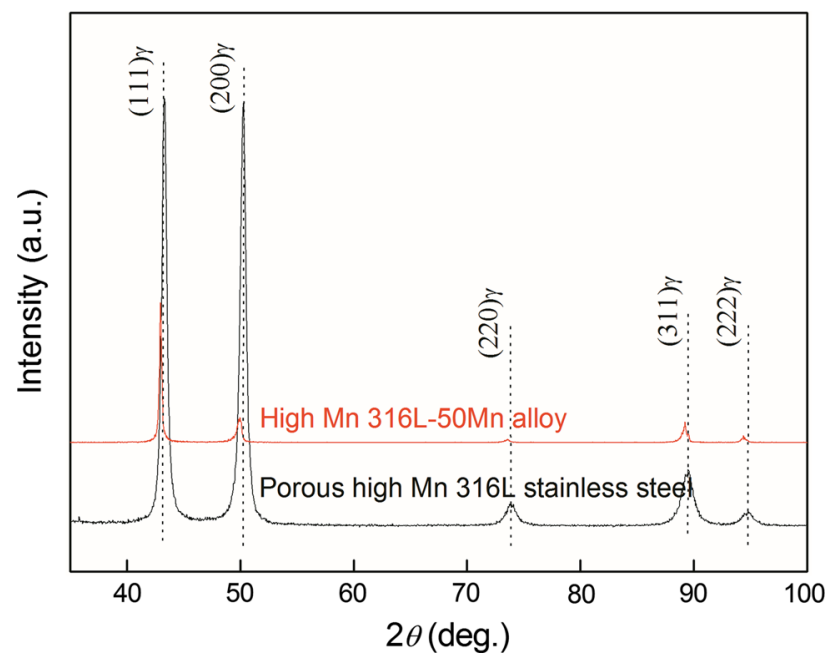

Fig. 1 X-ray diffraction patterns of the experimental high-manganese $316 \mathrm{~L}-50 \mathrm{Mn}$ alloy and porous high-manganese $316 \mathrm{~L}$ stainless steel

manganese. The samples with a dimension of $10 \mathrm{~mm} \times 10 \mathrm{~mm} \times 0.5 \mathrm{~mm}$ were sectioned by wire electrode cutting and then polished to $5 \mathrm{~mm} \times 5 \mathrm{~mm} \times$
$0.2 \mathrm{~mm}$ with $\mathrm{SiC}$ papers of $200-1000$ grit size and rinsed with absolute ethyl alcohol before physical dealloying.

The dealloying operation was performed at 750,800 , 850 and $900{ }^{\circ} \mathrm{C}$ for $3 \mathrm{~h}$ in dynamic high vacuum environment, respectively, and the vacuum degree was kept under $10 \mathrm{~Pa}$ or lower during dealloying experiments. Three parallel samples were operated for each test condition, and the average pore size distribution of the samples was measured. The surface morphology and crystal structure of the dealloyed samples were characterized, respectively, by scanning electron microscopy (SEM) equipped with energy-dispersive X-ray spectroscopy (EDS) and X-ray diffraction (XRD), respectively.

\section{Result and Discussion}

Figure 1 shows XRD patterns of the as-prepared highmanganese 316L-50Mn alloy and micron porous highmanganese $316 \mathrm{~L}$ stainless steel at $800{ }^{\circ} \mathrm{C}$ with the best porous structure, indicating that both the high-manganese $316 \mathrm{~L}-50 \mathrm{Mn}$ alloy and porous high-manganese $316 \mathrm{~L}$
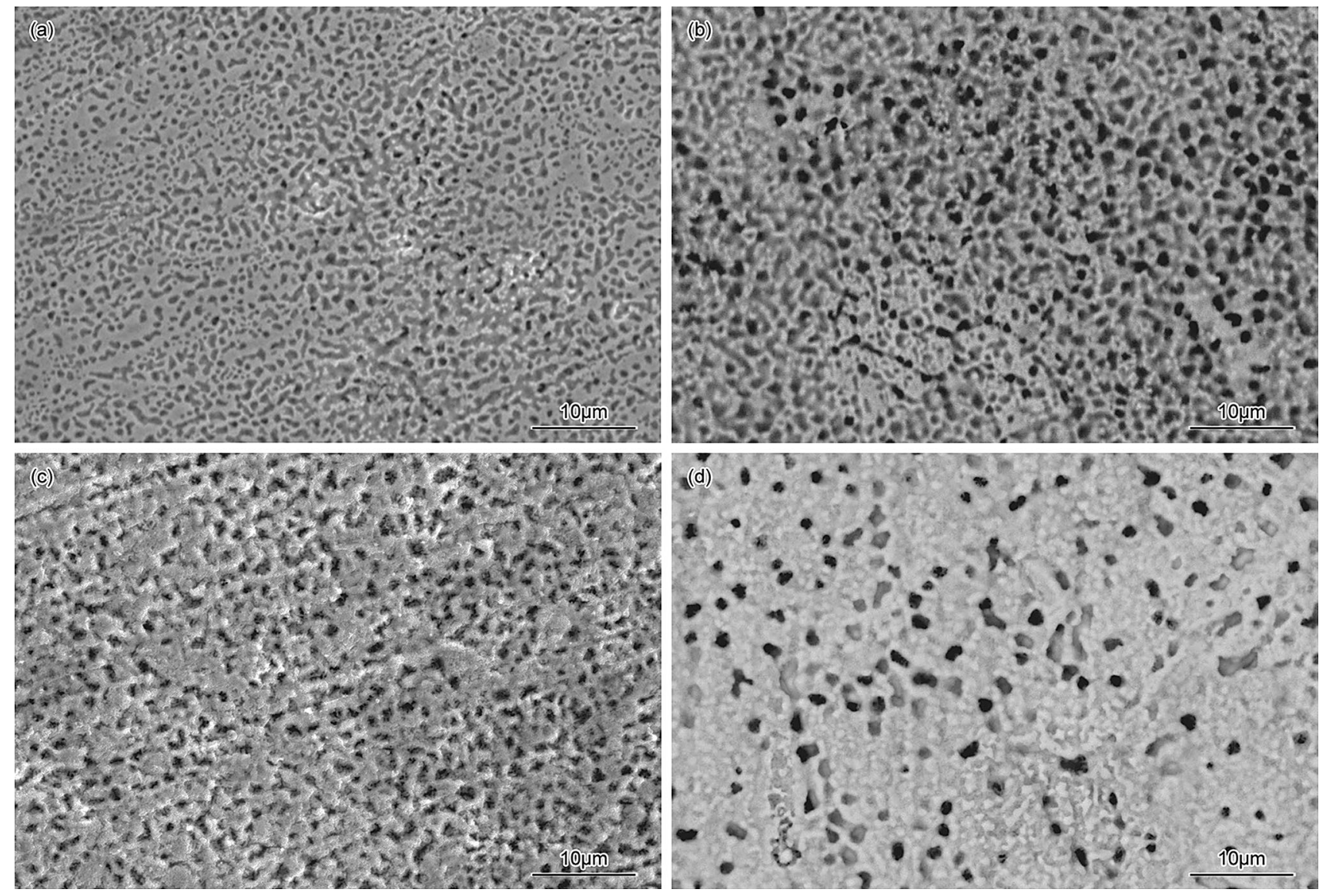

Fig. 2 SEM images of the porous high-manganese $316 \mathrm{~L}$ stainless steel after physical dealloying: a $750{ }^{\circ} \mathrm{C} ; \mathbf{b} 800{ }^{\circ} \mathrm{C} ; \mathbf{c} 850{ }^{\circ} \mathrm{C} ; \mathbf{d} 900{ }^{\circ} \mathrm{C}$ 
Table 1 The saturated vapor pressure of $\mathrm{Fe}$ and $\mathrm{Mn}$ at different temperatures

\begin{tabular}{|c|c|c|c|c|c|c|c|c|c|}
\hline \multirow[t]{2}{*}{ Element } & \multicolumn{4}{|c|}{$\lg p(\mathrm{mmHg})=A T^{-1}+B \lg T+C T+E$} & \multicolumn{4}{|c|}{ Saturated vapor pressure $(\mathrm{Pa})$} & \multirow[t]{2}{*}{ Temperature range $\left({ }^{\circ} \mathrm{C}\right)$} \\
\hline & $A$ & $B$ & $C$ & $E$ & $750{ }^{\circ} \mathrm{C}$ & $800{ }^{\circ} \mathrm{C}$ & $850^{\circ} \mathrm{C}$ & $900{ }^{\circ} \mathrm{C}$ & \\
\hline $\mathrm{Fe}$ & -21080 & -2.14 & - & 16.89 & $9.26 \times 10^{-9}$ & $7.63 \times 10^{-8}$ & $5.19 \times 10^{-7}$ & $2.98 \times 10^{-6}$ & $627-1539$ \\
\hline $\mathrm{Mn}$ & -14850 & -2.52 & - & 17.88 & $8.0 \times 10^{-3}$ & $3.37 \times 10^{-2}$ & $1.24 \times 10^{-1}$ & $4.07 \times 10^{-1}$ & $720-1100$ \\
\hline$p_{\mathrm{Mn}} / p_{\mathrm{Fe}}$ & - & - & - & - & $8.64 \times 10^{5}$ & $4.42 \times 10^{5}$ & $2.39 \times 10^{5}$ & $1.37 \times 10^{5}$ & - \\
\hline
\end{tabular}

stainless steel consist of one single austenitic phase, and no martensitic phase or any other secondary phase could be detected. Compared to normal 316L stainless steel, the peak positions of (111), (200), (220), (311) and (222) lattice planes in the precursor high-manganese $316 \mathrm{~L}$ stainless steel had about $0.3^{\circ}$ deviation. However, after physical dealloying, these peak positions in porous samples had nearly similar degrees to normal $316 \mathrm{~L}$ stainless steel, which reveals the transformation from rich manganese austenite structure to low manganese austenite structure after the physical dealloying process.

Figure 2 shows the surface SEM images of the highmanganese $316 \mathrm{~L}$ stainless steel after physical dealloying at $750,800,850$ and $900{ }^{\circ} \mathrm{C}$, respectively. Porous stainless steel can be prepared by physical dealloying with suitable temperature $\left(750-900{ }^{\circ} \mathrm{C}\right)$. The pores sizes are about $0.5-2 \mu \mathrm{m}$, but the widths of channel and ligament of porous stainless steels show great differences after dealloying treatment under different temperatures. The channel and ligament of micron porous stainless steels are non-uniform, as showed a very shallow pore on the dealloyed sample at $750{ }^{\circ} \mathrm{C}$ compared to other temperatures.

As temperature increased to $800{ }^{\circ} \mathrm{C}$, the micron porous stainless steel exhibited a well-developed three-dimensional continuous porous structure with ordered shape. The size distribution of the pores is from 1 to $3 \mu \mathrm{m}$, and the channels and ligaments are smoother and uniform. However, with increasing vacuum heat treatment temperature, the pores of porous stainless steel were fused gradually and the ligaments size began to grow up, resulting in less and less pores and the anomalous porous structure. The ligament of porous highmanganese 316L stainless steel samples was growing with increasing treatment temperature, and its sizes were growing into discontinuous surface with some voids when the treatment temperature was at $900{ }^{\circ} \mathrm{C}$; then, relative pores were obviously lesser than those at lower temperature.

In the present study, the Mn in the high-manganese $316 \mathrm{~L}-$ $50 \mathrm{Mn}$ alloy was the key element to prepare the micron porous stainless steel. As is known to all, single substance has a unique vapor pressure at a set temperature; in addition, high vapor pressure of manganese has a key influence on physical dealloying. Sublimation of Mn element was the primary reason to prepare porous stainless steel for physical dealloying in vacuum environment, so the gap of the saturated
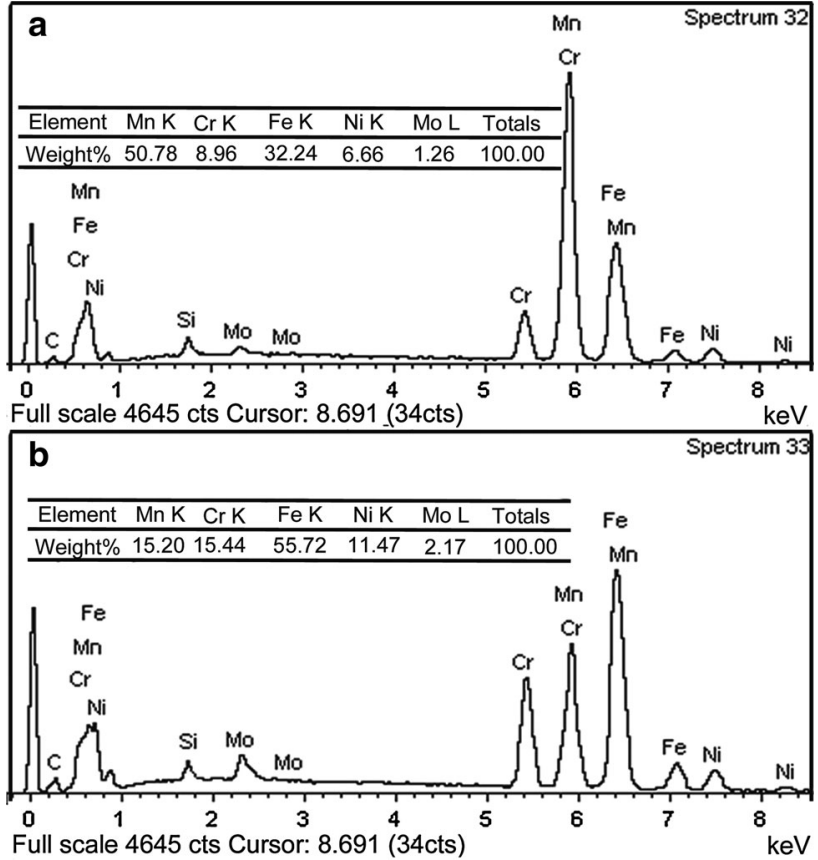

Fig. 3 EDS analyses of the experimental high-manganese 316L$50 \mathrm{Mn}$ alloy a, porous high-manganese $316 \mathrm{~L}$ stainless steel b

vapor pressure between diverse elements in alloy was very important. The relationship between saturated vapor pressure and temperature of pure metal was given by the following formula [14]: $\lg p \quad(\mathrm{mmHg})=A T^{-1}+B \lg T+$ $C T+E$, where $A, B, C, E$ are constants for manganese and iron, $T$ is temperature $(\mathrm{K}), p$ is vapor pressure $(\mathrm{mmHg})$.

Saturated vapor pressures of elements in high-manganese 316L-50Mn alloy are shown in Table 1. The saturation vapor pressures of $\mathrm{Mn}$ are much higher than those of $\mathrm{Fe}$, as the ratios $p_{\mathrm{Mn}} / p_{\mathrm{Fe}}$ were beyond $1.37 \times 10^{5}$ when the vacuum dealloying treatment temperatures were ranging from 750 to $900{ }^{\circ} \mathrm{C}$. Therefore, Mn with high saturation vapor pressure can be sublimated under vacuum condition, while most of the Fe remains in the matrix. According to thermodynamics of sublimation, the sublimation ratio exactly equals the rate of condensation back upon the surface of the matrix when a vapor is in equilibrium with a solid. So the dynamic high vacuum environment kept to increase the sublimation ratio of Mn during the dealloying process. Figure 3 shows EDS analyses of the as-prepared high-manganese 316L-50Mn 
Table 2 The diffusion coefficient of $\mathrm{Fe}$ and $\mathrm{Mn}$ at different temperatures

\begin{tabular}{|c|c|c|c|c|c|c|c|}
\hline \multirow[t]{2}{*}{ Base metal } & \multirow[t]{2}{*}{ Diffusion element } & \multicolumn{2}{|c|}{$D=D_{0} \mathrm{e}^{-Q / R T}$} & \multicolumn{4}{|c|}{ Diffusion coefficient $\left(\mathrm{m}^{2} \mathrm{~s}^{-1}\right)$} \\
\hline & & $D_{0}\left(\mathrm{~m}^{2} \mathrm{~s}^{-1}\right)$ & $Q\left(\mathrm{~kJ} \mathrm{~mol}^{-1}\right)$ & $750^{\circ} \mathrm{C}$ & $800{ }^{\circ} \mathrm{C}$ & $850^{\circ} \mathrm{C}$ & $900{ }^{\circ} \mathrm{C}$ \\
\hline \multirow[t]{2}{*}{$\gamma-\mathrm{Fe}$} & $\mathrm{Fe}$ & $1.05 \times 10^{-4}$ & 283.9 & $3.35 \times 10^{-19}$ & $1.59 \times 10^{-18}$ & $6.54 \times 10^{-18}$ & $2.39 \times 10^{-17}$ \\
\hline & $\mathrm{Mn}$ & $0.16 \times 10^{-4}$ & 261.7 & $6.94 \times 10^{-19}$ & $2.91 \times 10^{-18}$ & $1.07 \times 10^{-17}$ & $3.50 \times 10^{-17}$ \\
\hline
\end{tabular}

alloy and micron porous high-manganese $316 \mathrm{~L}$ stainless steel from sample at $800{ }^{\circ} \mathrm{C}$ (the best porous structure), indicating that most of the manganese elements in highmanganese $316 \mathrm{~L}$ stainless steel were sublimated at $800{ }^{\circ} \mathrm{C}$ for $3 \mathrm{~h}$, although $\mathrm{Mn}$ content in porous high-manganese 316L stainless steel was more higher than normal 316L. If the vacuum dealloying treatment time increases, manganese will be reduced to a relative low content.

In this paper, preparation of the porous stainless steel also depended on the differential diffusion of Kirkendall effect according to our previous work [6-9]. The Kirkendall effect is a classical phenomenon in metallurgy, which is a consequence of the different diffusivities of atoms in a diffusion couple, causing a supersaturation of lattice vacancies. This supersaturation may lead to a condensation of extra vacancies in the form of so-called Kirkendall voids $[15,16]$. According to Kirkendall effect, the Kirkendall voids would be generated only when the diffusion rate of $\mathrm{Mn}$ through the high-manganese 316L$50 \mathrm{Mn}$ alloy was faster than that of $\mathrm{Fe}$ at a set temperature. The diffusion rate of metal element in alloy usually depends on its diffusion coefficient according to Fick's diffusion law. The relationship between diffusion coefficient and temperature was given by the following Arrhenius equation [14]: $D=D_{0} \mathrm{e}^{-Q / R T}$, where $D_{0}$ represents frequency factor and $Q$ represents the diffusion activation energy $(\mathrm{J} / \mathrm{mol})$, and the data of diffusion coefficient of main elements in the high-manganese $316 \mathrm{~L}-50 \mathrm{Mn}$ alloy are shown in Table 2. The diffusion coefficients of $\mathrm{Mn}$ are higher than of $\mathrm{Fe}$ from 750 to $900{ }^{\circ} \mathrm{C}$, especially at $850{ }^{\circ} \mathrm{C}$. According to Kirkendall void effect, owing to the faster diffusion of Mn atoms, a lot of vacancies would be formed in high-manganese stainless steel, and vacancies coalesce to form pores or voids in the alloy.

The temperature was also an essential factor for physical dealloying in this study, which is not only involved of the sublimation speed of $\mathrm{Mn}$, but also affected the diffusion speed of Mn in stainless steel. According to the relationship between saturated vapor pressure and temperature, the saturated vapor pressure of Mn would increase with temperature increased, and pores in porous stainless steel would be formed easily. However, in fact, it partly merged together (Fig. 2d). Obviously, the diffusion speed of Fe was also increased with temperature increased, and then, most of the lattice vacancies formed in migration of $\mathrm{Mn}$ would be occupied by Fe atoms; therefore, many small Kirkendall voids would disappear. So the physical dealloying in vacuum environment can occur at an optimized temperature for some special alloys. The optimum physical dealloying temperature for the high-manganese $316 \mathrm{~L}-50 \mathrm{Mn}$ alloy was between 800 and $850{ }^{\circ} \mathrm{C}$ in the present study.

\section{Conclusions}

In summary, the micron porous high-manganese 316L stainless steel was simply prepared using the high-manganese 316L-50Mn alloy by physical dealloying method. It showed a three-dimensional continuous porous structure with 1-2 $\mu \mathrm{m}$ pore size. And the temperature was the key factor for the physical dealloying process, and the optimized treatment temperature was between 800 and $850{ }^{\circ} \mathrm{C}$ for the porous highmanganese $316 \mathrm{~L}$ stainless steel in the present study.

Acknowledgement This work was supported by the National Natural Science Foundation of China (Grant No. 31370976).

\section{References}

[1] L. Lefebvre, J. Banhart, D. Dunand, Adv. Eng. Mater. 10, 775 (2010)

[2] C. Li, B. Jiang, Z. Wang et al., Angew. Chem. Int. Ed. Engl. 41, 12746 (2016)

[3] V. Malgras, H. Ataee-Esfahani, H. Wang et al., Adv. Mater. 6, 993 (2016)

[4] B. Jiang, C. Li, J. Tang et al., Angew. Chem. Int. Ed. Engl. 34, 10037 (2016)

[5] B. Jiang, C. Li, V. Malgras et al., Chem. Sci. 2, 1575 (2016)

[6] H. Jiang, Q. Xu, Chem. Commun. 47, 3351 (2011)

[7] S. Molin, M. Gazda, B. Kusz, J. Eur. Ceram. Soc. 29, 757 (2009)

[8] H. Bakan, Scripta Mater. 55, 203 (2006)

[9] P. Liu, B. Yu, A. Hu, K. Liang, S. Gu, J. Mater. Sci. Technol. 18, 299 (2002)

[10] Y. Ren, Y. Sun, K. Yang, Acta Metall. Sin. (Engl. Lett.) 29, 1144 (2016)

[11] Y. Sun, Y. Ren, K. Yang, Mater. Lett. 165, 1 (2016)

[12] Y. Sun, Y. Ren, Vacuum 122, 215 (2015)

[13] Y. Ren, Y. Sun, K. Xiao, K. Yang, China Patent CN201,410,181,273.0 (2014)

[14] E. Brandes, G. Brook. Smithells metals reference book, 7th edn. (Elsevier, 1998). http://www.seg.org/reviews/mccorm30.html

[15] E. Kirkendall, L. Thomassen, C. Upthegrove, Trans. AIME. 133, 186 (1939)

[16] R. Honig, D. Kramer, RCA Rev. 30, 285 (1969) 